\title{
ORGANIZAÇÕES SOCIAIS E INSTRUMENTOS DE GESTÃO: O DEBATE NO CONSELHO ESTADUAL DE SAÚDE DE SANTA CATARINA (CES/SC)
}

\author{
Tầnia Regina Krüger*
}

\begin{abstract}
Resumo
O objetivo deste artigo é conhecer e refletir como o Conselho Estadual de Saúde de Santa Catarina (CES/SC), ao pautar os instrumentos de gestão (Plano Estadual de Saúde, Programação Anual de Saúde, Prestação de Contas Quadrimestrais e Relatório Anual de Gestão) debateu, questionou e deliberou sobre os serviços estaduais de saúde entregues à gestão de Organizações Sociais (OS) - em um contexto de graves afrontas aos fundamentos do SUS. Para este estudo foram consultadas as atas disponíveis online do CES/SC, do período de 2005 a 2015. No texto, inicialmente apresentamos o marco regulatório e reflexões sobre o significado das Organizações Sociais nos serviços do SUS como uma forma de privatização não clássica dos serviços públicos. Do estudo das atas, resultou um item sobre como o tema da gestão dos serviços estaduais de saúde sob a gestão de OS foi debatido e decidido pelo Conselho Estadual de Saúde quando a pauta era os instrumentos de gestão. As tensões em termos de perspectiva política, as descontinuidades do tema em pauta, as ênfases gerencialista e legalista são as principais marcas do debate das OS no CES/SC.
\end{abstract}

Palavras-chave: SUS. Organizações Sociais. Instrumentos de Gestão. Conselho de Saúde.

\footnotetext{
* Assistente Social, mestre em Educação pela Universidade Estadual de Santa Catarina (UDESC) e doutora em Serviço Social pela Universidade Federal de Pelotas (UFPel), docente no Programa de Pós-Graduação Stricto Sensu em Serviço Social da Universidade Federal de Santa Catarina (PPGSS/UFSC), integrante do Núcleo de Estudos em Serviço Social e Organização Popular (NESSOP) e da linha de pesquisa Participação popular e políticas sociais. E-mail: tania.kruger@ufsc.br
} 


\section{Introdução}

Após a Carta Constitucional de 1988, as decisões dos espaços de participação popular devem avaliar e deliberar sobre a gestão das políticas sociais ao mesmo tempo em que a gestão é integrante dos espaços de participação; mas, parece que a gestão enquanto atividade técnica e executiva se distancia do espaço político da participação social. A administração pública do Estado brasileiro historicamente tem conseguido tomar suas decisões sem envolver a participação das classes populares por meio de decisões autoritárias, clientelistas e patrimonialistas. Por sua vez, as classes populares historicamente não foram reconhecidas como sujeitos políticosparticipantes da gestão da coisa pública. ${ }^{1}$ Formalmente, no caso das políticas sociais, esta distância e este vazio entre a gestão pública e a participação popular se alteraram, já que os direitos sociais reconhecidos em 1988 possuem entre seus princípios doutrinários e organizacionais a participação popular.

Do ponto de vista da gestão, entendemos que as ações de um governo afetam todos os membros de uma sociedade; portanto, em um Estado democrático, todos os membros desta sociedade têm o direito de exercer influência sobre o governo, isto é, participar na tomada de decisões. Uma gestão democrática deve ser permeável às demandas e reivindicações dos trabalhadores, o que significa a democratização das decisões, as quais se materializam no planejamento, no financiamento, na execução e na avaliação dos serviços. Uma gestão democrática de fato implica reconhecer necessidades sociais de grupos historicamente excluídos, reconhecer suas necessidades sociais e de saúde, reconhecer suas expressões políticas, não mais pela lógica do clientelismo e patrimonialismo, e sim pela lógica do direito e da igualdade real.

E o desafio das últimas décadas é tentar alterar as bases desta cultura política de gestão pública tradicional, resistir à perspectiva gerencialista e construir uma nova que se sustente em bases democrático-populares, sobretudo na gestão das políticas sociais. A Constituição criou um lugar institucional
1 Ver referências históricas acerca da administração pública do Estado brasileiro em: Sales, 1993; Ianni, 1984; Nogueira, 1998; Fernandes, 2006; Prado Jr., 2011. 
para os sujeitos populares nas políticas sociais, mas não criou mecanismos de participação popular que atuam em relação à política econômica, o sistema político e o sistema de informação e comunicação. Essas esferas são dimensões fundamentais de um Estado democrático; mas, logo, já colocam vários limites para uma gestão participativa nas políticas sociais. Assim, nós nos perguntamos: quais as possibilidades de uma gestão com sistema descentralizado e participativo para a área das políticas sociais quando a área econômica continua com a centralização do poder de decisão? Não se faz política social sem política econômica. $\mathrm{Ou}$, melhor, porque estas duas esferas da política não se comunicam e possuem pesos políticos muitos diferentes, a política social tem sido historicamente subordinada, secundarizada e, por isso, sofre descontinuidades, é organizada de forma focalizada e seletiva.

Enquanto as políticas sociais estiverem subordinadas à política econômica que reforça as desigualdades sociais e o reconhecimento do direito social apenas do ponto de vista formal, não se potencializa o enfrentamento das iniquidades sociais. A igualdade jurídico-formal, como fundamento da democracia e da cidadania, é um recurso que uma gestão que se pretenda democrática não pode desconhecer, nem se limitar a reproduzi-la. Uma gestão democrática não se reduz a uma valorização abstrata dos fundamentos da igualdade jurídico-formal, mas tem de inscrever-se em uma outra relação do Estado com a sociedade e com a distribuição da riqueza social produzida. A universalização democrática com exercício pleno e real da participação social e política não tem se dado historicamente deste modo, mas sim pela mediação da prática política das classes e grupos sociais em presença (NETTO, 1990).

$\mathrm{Da}$ forma como que se organizaram as políticas sociais no Brasil, forjou-se um quadro de que quem trabalha com política social não precisa se envolver, nem conhecer as determinações da política econômica. A gestão pública e a formação dos trabalhadores das áreas econômica e social se estruturaram separando estas duas dimensões da administração 
da vida pública do país. Devido a isso, em momentos de mobilização social por parte das classes populares, como foram os anos de 1980, o poder dominante atendeu parcialmente as reivindicações, permitindo no capítulo dos direitos sociais da Carta Constitucional o princípio da participação popular. A redemocratização - ainda que movida dentro da racionalidade da classe dominante, pois a transição política da ditadura foi controlada por ela, a cidadania brasileira - fez desta década um período de lutas e colocou no horizonte da gestão das políticas sociais a perspectiva da democracia e as necessidades da classe trabalhadora. As gestões com retórica democrática que se disseminaram, sobretudo a partir dos anos 2000 pelos governos nos diferentes entes federados do Brasil, em si não geram inclusão social, nem distribuição da riqueza socialmente produzida, e não garantem que as demandas nascidas nos espaços colegiados de participação social sejam contempladas e não socializam de fato o poder político.

Particularmente no contexto da redemocratização o Sistema Único de Saúde (SUS), foi resultado de inúmeras lutas sociais e se constituiu, nas últimas décadas, como um dos maiores sistemas públicos de saúde do mundo, que oferece serviços de saúde com acesso universal, atendimento integral e igualitário aos brasileiros. O SUS está garantido nos artigos 196 a 200 da Constituição Federal de 1988 e através da Lei no $8.080 / 90$. A criação do SUS se deu a partir do movimento social da Reforma Sanitária que tinha como pauta principal a defesa da saúde como direito fundamental de cidadania. Para o Movimento Sanitário a saúde não pode ser considerada apenas como ausência da doença, mas como resultante de um conjunto de determinações socioeconômicas. Esta perspectiva se opunha a um sistema de saúde privado, com base em medicina de consultório, com médicos particulares, ao crescimento do empresariamento da medicina, clínicas particulares que faziam convênios com o Inamps e viviam mediante pagamento por unidade de serviços. Desta luta social da Reforma Sanitária contra o modelo liberal privatista, médico-centrado e curativo, decorreu o reconhecimento 
constitucional da saúde como direito de todos e dever do Estado, tendo como diretrizes a integralidade da assistência, a participação da comunidade e descentralização políticoadministrativa, devendo ser organizado um Sistema Único de Saúde (SUS) para prestar assistência com base nas normas do direito público (KRÜGER, 2012).

A partir dos anos 1990, mesmo com o SUS regulamentado, temos um cenário de disputa políticoideológico, no qual o projeto liberal privatista da saúde continua evidenciando sua expressividade. Este projeto, conforme Bravo (2006), tem como objetivo que o Estado garanta um mínimo aos que não podem pagar, deixando a cargo do setor privado o atendimento dos que têm acesso ao mercado. O projeto liberal privatista tem como propostas o atendimento às populações vulneráveis por meio do pacote básico para a saúde sob a responsabilidade do Estado, da descentralização dos serviços ao nível local, da quebra do financiamento $100 \%$ público do SUS, a ampliação das contratualizações com os serviços privados e filantrópicos, a entrega dos serviços públicos de saúde à gestão de empresas denominadas de Organizações Sociais, a criação de empresas públicas para prestar e gerir os serviços de saúde com base no direito privado, a renúncia fiscal beneficiando o setor filantrópico e privado da saúde e o estímulo ao seguro privado de saúde.

Em 1999 o Governo Federal sancionou a Lei n. ${ }^{\circ}$ 9.637/98 - a Lei das Organizações Sociais, a qual consiste em um novo modelo de gestão da saúde conferindo a entidades teoricamente sem fins lucrativos, qualificadas como Organizações Sociais de Saúde (OS), o gerenciamento de hospitais e equipamentos públicos de saúde. As OS são empresas de direito privado que recebem os recursos públicos para administrar as unidades de saúde com total autonomia para contratação de funcionários sem concursos públicos, compras sem licitações, com liberdade na gestão dos serviços, podendo inclusive cobrar por eles. As OS não passam pela fiscalização do controle social, sua fiscalização acontece por 
meio de uma comissão indicada majoritariamente pelo governo - Comissão de Acompanhamento e Fiscalização (CAF) - que deve reunir-se apenas trimestralmente. Depois de firmado o Contrato de Gestão com a esfera de governo correspondente, a Organização Social passa a receber recursos orçamentários para administrar serviços, instalações e equipamentos do Poder Público (CORREIA; SANTOS, 2015).

Assim, a partir dessas determinações que colocaram graves afrontas e ameaças aos fundamentos do $\mathrm{SUS}^{2}$, o objetivo deste artigo é conhecer e refletir como o Conselho Estadual de Saúde de Santa Catarina, ao pautar os instrumentos de gestão (Plano Estadual de Saúde, Programação Anual de Saúde, Prestação de Contas Quadrimestrais e Relatório Anual de Gestão), debateu, questionou e deliberou sobre os serviços estaduais de saúde entregue a gestão de OS. Para este estudo foram consultadas as atas disponíveis online do Conselho Estadual de Saúde (CES/SC), do período de 2005 a 2015, ao todo 97 atas, que são as do número 111 a 211. Destacase que, nas referências, as atas do CES/SC não omitiram os nomes dos conselheiros, tendo em vista que são documentos públicos e estão disponibilizadas na rede mundial de computadores. Da mesma forma, a função dos conselheiros é publica e sua atuação pauta-se na lógica da democracia representativa de cada um dos quatro segmentos (usuários, trabalhadores, gestores públicos e prestadores privados para o SUS) que compõem este colegiado deliberativo da política estadual de saúde.

Este texto estrutura-se nos seguintes itens. Inicialmente, traz reflexões sobre o significado das Organizações Sociais nos serviços do SUS como uma forma de privatização não clássica dos serviços públicos. $\mathrm{Na}$ sequência, apresenta o marco regulatório das OS em nível nacional e estadual. Como terceiro item, faz uma síntese sobre como o tema da gestão dos serviços públicos estaduais de saúde sob a gestão de OS foi debatido e decidido pelo Conselho Estadual de Saúde quando a pauta era os instrumentos de gestão (Plano Estadual de Saúde, Programação Anual de Saúde, Prestação de Contas
2 Entendemos como fundamentos do SUS os seguintes itens: a) conceito ampliado de saúde; b) determinação social da saúde; c) objetivos do SUS (art. 5o Lei no 8.080/90); d) competências do SUS (art. 6o Lei no 8.080/90); e) princípios do SUS (art. $7^{\circ}$ Lei no 8.080/90) e f) gestão Estatal com base no direito Público. $\mathrm{O}$ que chamamos de graves afrontas e ameaças aos fundamentos do SUS continua acontecendo nas duas décadas dos anos 2000, sendo agravadas pela conjuntura brasileira a partir de 2016 e 2017. 
Quadrimestrais e Relatório Anual de Gestão). As tensões em termos de perspectiva política, as descontinuidades do tema em pauta e a ênfase gerencialista e legal são as principais marcas do debate das OS no CES/SC, são mais bem desenvolvidas nas considerações finais. A participação da sociedade civil na deliberação dessa política social reproduz elementos tradicionais da nossa cultura política ao mesmo tempo em que alarga as fronteiras do Estado de debate com a sociedade.

\section{Organizações Sociais nos serviços do SUS: uma forma de privatização não clássica}

Nos anos de 1990 e 2000 observou-se, no Estado brasileiro, a intensificação das ideologias e de práticas de gestão pautadas na contrarreforma, as quais submetem progressivamente as necessidades sociais aos interesses econômicos. Em paralelo, a redução do tamanho do Estado no atendimento às necessidades essenciais da cidadania vem se sustentando a concepção de que não cabe ao Estado à responsabilidade de provisão social, e sim à sociedade (mercado).Essa lógica vem instaurando progressivamente uma nova racionalidade em termos políticos, ideológicos, culturais para gestão das políticas sociais, ao permitir que se transforme parte do patrimônio público em serviços mercantis. Essa racionalidade despreza a cultura forjada nos anos de 1980 e a trata como uma espécie de nostalgia da esquerda democrática, com o fim de despolitizar o conjunto das relações sociais, em nome da liberdade do mercado e do fim das ideologias (MOTA; AMARAL, 2014).

Nessa perspectiva, a Constituição Federal e os direitos sociais ali garantidos parecem ser um mero detalhe que não deve ser levado em consideração quando se tratar de atender aos interesses do setor econômico. E, nessa lógica, deixa de ser necessário discutir os termos da Constituição. Basta dizer, então, que quem faz menção à existência da Constituição é ideológico, fazendo supor que quem a despreza é moderno ou antenado com os novos tempos (SOUTO MAIOR, 2017). 
Esse projeto de contrarreforma cinde economia e política como se não fossem uma totalidade, igualmente separa teoria e prática, como se as exigências de ajustes e reformas fossem apenas necessidade técnica, escamoteando o projeto dominante que pretende se universalizar. Essa ofensiva ideológica reforça apelos sobre as possibilidades de mobilidade social, de crescimento do consumo, de aumento de emprego formal, oportunidades de qualificação profissional, promete modernização da gestão pública e das práticas empresariais, estímulo a negócios próprios/empreendedorismo (chamadas de políticas ativas de trabalho e renda). Essa ofensiva política, cultural, ideológica e econômica para obter a adesão, o consentimento dos trabalhadores e legitimar suas práticas (MOTA; AMARAL, 2014, p. 31) possui uma retórica que envolve a subjetividade e apela para as necessidades mais básicas de sobrevivência.

Segundo Souza Filho (2006, p. 323), a hegemonia ideológica do:

[...] projeto gerencialista ataca a finalidade de universalização de direitos e sua dimensão racional/ impessoal da ordem administrativa burocrática que potencializaria aquela finalidade. Ratifica-se uma finalidade fundada no atendimento de necessidades mínimas da população, coerente com a proposição neoliberal de reforço do mercado, e na mudança da estrutura burocrática para flexibilizá-la, na medida em que não se propõe a universalização de direitos.

Por sua vez, apresentamos o entendimento sobre administração pública gerencial de seus idealizadores e da elite política e econômica que o defende a:

[...] administração pública gerencial é aquela construída sobre bases que consideram o Estado uma grande empresa cujos serviços são destinados aos seus clientes, outrora cidadãos; possui, na eficiência dos serviços, na avaliação de desempenho e no controle de resultados, suas principais características. (MAFRA, 2005, p. 1). 
Para Mafra (2005), a administração pública gerencial é consequência dos avanços tecnológicos e da nova organização política e econômica mundial, para tornar o Estado capaz de competir com outros países. Por isso, o Estado tem como objetivos principais atender a duas exigências do mundo atual: adaptar-se à revisão das formas de atuação do Estado, que são empreendidas nos cenários de cada país; e atender às exigências das democracias de massa contemporâneas. O pensamento favorável a esse novo modelo resume-se à constatação de que o Estado burocrático não é mais capaz de atender às exigências democráticas do mundo atual.

Essa caracterização da administração pública gerencial deixa evidente que se pauta na proposta de esvaziamento do papel do Estado de regulador das relações sociais e de mercado. $\mathrm{Na}$ sua lógica, o projeto gerencialista se apresenta como uma dimensão autônoma e independente da política e da economia, transformando a dimensão política da gestão pública e dos direitos sociais em uma dimensão técnica-operacional, como decorrência natural das exigências do mundo atual. Na prática do Estado brasileiro, vimos o Ministério da Fazenda e o Ministério do Planejamento como o núcleo responsável pelas decisões, sobretudo no que se refere à política econômicofinanceira, controlando as informações estratégicas; assim, aos demais ministérios cabe uma posição relativamente periférica, em geral tendo conhecimento das decisões depois destas terem sido tomadas e restando a função de acatar ou implantar. Em síntese, o gerencialismo desideologiza a política e despolitiza a gestão em nome de uma racionalidade, de uma legalidade, combinada com estratégias de flexibilização gerencial, de modernização e de eficiência. Os valores democráticos, mesmo no seu viés burguês, e o avanço civilizacional que os direitos sociais representaram com a Carta de 1988 para o Brasil, são colocados como não correspondentes à lógica das exigências das democracias contemporâneas que se pauta em um modelo de Estado-empresa (SOUZA FILHO, 2013).

$\mathrm{Na}$ direção oposta ao projeto gerencialista, temos as conquistas de 1988 que preveem para a gestão pública a 
estruturação de uma ordem classicamente burocrática, no sentido do fortalecimento das dimensões de formalidade, mérito e impessoalidade da administração pública. Esse projeto que coloca a administração pública a serviço das necessidades sociais mostra um caminho democrático a ser seguido do ponto de vista político e institucional; portanto, antagônico à história de desenvolvimento do Estado brasileiro e de sua ordem administrativa. Busca articular um projeto para o país com base na incorporação substantiva da classe trabalhadora; por isso, a necessidade de um Estado forte na área social e o consequente fortalecimento da estrutura da burocracia, nas dimensões de impessoalidade e formalidade (SOUZA FILHO, 2013).

No tempo de implantação dessa ordem burocrática prevista em 1988, vimos sim a intensificação do poder econômico sobre todas as instâncias da vida social, desenvolvendo-se com as contrarreformas gerencialista uma lógica de que as políticas sociais podem ser realizadas nos moldes análogos aos serviços privados. No campo das políticas sociais, estes não tem se desenvolvido classicamente como um serviço privado. As empresas que estão se especializando nesta fatia de mercado estão extraindo sobremaneira recursos do fundo público. São exemplo de empresa que extrai e sobrevive unicamente de recurso do fundo público para realizar algum serviço de política social as Organizações Sociais, as quais, por meio contrato com base no direito privado, fazem a gestão de unidades públicas e prestam serviço do SUS. Serviço que caracterizaremos adiante, com base em Granemann (2011), como um modelo de privatização não clássica.

Segundo Granemann (2011), para as políticas sociais os governantes das mais diferentes filiações partidárias notaram que, para a transferência do fundo público aos capitais, não seria recomendável seguir a mesma forma de privatização clássica porque poderia provocar reações de insatisfação popular. Ou seja, as instituições brasileiras que prestam os serviços básicos de cidadania, de natureza social e que devem garantir a dignidade humana não poderiam ser entregues ao 
setor privado tradicional na mesma lógica do que as empresas públicas de natureza econômica e de serviços tarifados (por meio de cotações na bolsa de valores - a privatização clássica). Assim a privatização não clássica é uma forma aprofundada de privatização, e se faz por convênios, edital de licitação e com mudança na natureza das instituições públicas de direito público para instituições públicas regidas pelo direito privado. A privatização não clássica é chamada assim porque não se realiza pelo mecanismo da venda típica, mas por meio de contrato, e envolve no plano dos argumentos uma afirmação de que tal mecanismo operará com mais e não menos Estado.

A entrega da gestão das políticas sociais a entes pautados no direito privado se deve a toda uma satanização do Estado, segundo Borón (1996), que vem se afirmando desde o início dos anos de 1990 a partir de um clima ideológico, com divulgação das ideias de que o Estado não é competente, é lento, seus trâmites burocráticos são morosos, ineficientes, sofre ingerências políticas, e que todas estas qualidades e virtudes se encontram na gestão dos serviços privados. Esse clima ideológico se solidificou na avaliação de Nogueira (1998, p. 124), quando as forças neoliberais vieram "[...] a público proclamar que o Estado simbolizava o atraso indesejável e a constituição da modernidade por todos almejada dependia da negação do Estado".

A privatização não clássica se sustenta na perspectiva que reivindica melhoria do gerenciamento dos serviços públicos por meio da flexibilização, descentralização e modernização, ao mesmo tempo em que despolitiza as relações de classes presentes nas políticas sociais, enfatiza a técnica sobre a política e faz a política do capital (GRANEMANN, 2011). As políticas sociais, mesmo tendo seu caráter contraditório de ser ao mesmo tempo concessão do capital e conquista da classe trabalhadora, nessa ordem burocrática burguesa, têm por objetivo prestar serviços sociais à população que não consegue acessar no mercado. No mercado, a proteção social é mercadoria; assim, direitos básicos de cidadania se transformam em serviços vendidos no mercado, como: 
a previdência, o lazer, a saúde, a cultura, a educação, a alimentação, a habitação, os recursos naturais, a ciência e a tecnologia. Em síntese, a privatização não clássica transforma os direitos em mercadoria comprados no mercado e rebaixa o que são as atividades exclusivas do Estado.

Dessa forma, na impossibilidade legal e operacional da privatização clássica, ganha ênfase a privatização não clássica na saúde, visto que esta tem acontecido de maneira mais elaborada e perversa. O patrimônio continua sendo público; porém, a sua administração e literalmente, a sua exploração, é feita por grupos privados ou políticos organizados que o gerenciam de acordo com os seus interesses e para atender às suas demandas políticas, particulares ou de ampliação do negócio (GRANEMANN, 2011).

Essa forma de privatização não clássica das políticas sociais e particularmente na saúde tem duas grandes expressões: a) a entrega da gestão dos serviços públicos a pessoas jurídicas de direito privado como são as Organizações Sociais; b) a criação das Fundações Estatais de Direito Privado e de Empresas Públicas geridas pelo direito privado, como a Empresa Brasileira de Serviços Hospitalares - EBSERH e a Empresa Pública de Saúde do estado do Rio de Janeiro RioSaúde, são seus exemplos emblemáticos, entre outros, sendo a primeira destas expressões objeto deste estudo.

Desde 1988 a saúde é, na sociedade brasileira, um direito social humano de cidadania, isto é, muito mais que uma prestação de serviço social eventual ou uma mercadoria. E o principal sujeito responsável pela garantia, pela organização e pela operacionalização deste direito social é o Estado. Por isso, entendemos que toda a entrega da gestão das instituições da saúde a empresas privadas e públicas, ambas geridas pelo direito privado, é uma afronta do projeto gerencialista aos direitos sociais conquistados, tão caros à classe trabalhadora brasileira.

A privatização não clássica vem ganhando espaços nas instituições públicas de saúde a partir do fato de que os modelos de privatização clássica não são mais suficientes para 
a acumulação do capital. Temos assim, um retrocesso histórico na gestão dos serviços do SUS com esses modelos de gestão sendo cada vez mais fortalecidos pelo Estado. Para a execução e gestão destes serviços básicos de cidadania, o Estado estruturou um arcabouço legal para criação das Organizações Sociais - OS (Lei no 9.637/98 e Decreto no 3.100/99) que são instituições privadas, geridas pelas normas do Direito Privado e sem fins lucrativos, que podem realizar contratos com o Estado para a execução e gestão dos serviços públicos.

\section{Marco regulatório das OS em Santa Catarina}

A política do governo do estado de Santa Catarina para transferir a gestão dos serviços públicos às Organizações Sociais se instituiu com a implementação do Programa Estadual de Incentivo às Organizações Sociais (Art. $1^{\circ}$ da Lei no 13.720 , de 02 de março de 2006):

Tem como finalidade permitir a descentralização de atividades e serviços desempenhados por órgãos ou entidades públicos estaduais, para pessoas jurídicas de direito privado de fins não-econômicos [sic], dirigidos à assistência social, ao ensino, à pesquisa científica, à comunicação, ao desenvolvimento tecnológico, à proteção e preservação do meio ambiente, à cultura, ao turismo, ao esporte, à saúde e ao planejamento e gestão, para entidades da sociedade civil qualificadas como Organização Social na forma da Lei no 12.929, de 04 de fevereiro de 2004, alterada pelas Leis $\mathrm{n}^{\circ}$ 13.343 , de 10 de março de 2005 , e no 13.720 , de 02 de março de 2006, bem como disposto no Decreto ${ }^{\circ}$ 4.272, de 28 de abril de 2006. (SANTA CATARINA, 2015).

Segundo o art. 18, da Lei no 12.929/2004:

Poderão ser destinados às organizações sociais recursos orçamentários e bens públicos necessários ao cumprimento do contrato de gestão.

Artigo 30-A, da Lei no 13.343, de 10 de março de 2005: 
As extinções e a absorção de atividades e serviços por Organizações Sociais de que trata esta lei observarão os seguintes preceitos:

II - a desativação das unidades extintas será realizada mediante inventário de seus bens imóveis e de seu acervo físico, documental e material, bem como dos contratos e convênios, com a adoção de providências dirigidas à manutenção e ao prosseguimento das atividades sociais a cargo dessas unidades, nos termos da legislação aplicável em cada caso;

$\mathrm{V}$ - a Organização Social que tiver absorvido as atribuições das unidades extintas poderá adotar os símbolos designativos destes, seguidos da identificação “OS”. (SANTA CATARINA, 2004).

Já o art. 22, da Lei no 13.720/2006, determina que: "Para a execução do objeto do Contrato de Gestão, os órgãos e entidades da administração pública estadual poderão autorizar a participação de seus servidores nas atividades realizadas pelas Organizações Sociais" (SANTA CATARINA, 2006).

As Organizações Sociais, ao realizarem o contrato de gestão com o governo de Santa Catarina, receberão recursos orçamentários e patrimoniais, podendo ser disponibilizados servidores públicos com ônus para o estado e outros bens públicos necessários ao cumprimento das metas do contrato de gestão (SANTA CATARINA, 2015).

\section{Conselho Estadual de Saúde: o debate das Organizações Sociais e a deliberação sobre os instrumentos de gestão}

\section{A dinâmica de reunião do Conselho Estadual de Saúde}

Para este estudo, foram consultadas as atas disponíveis online do Conselho Estadual de Saúde - CES/SC, do período de 2005 a 2015. Ao todo estão disponibilizadas 97 atas no período, que são as do número 111 a $205^{3}$. A seguir, uma tabela com as reuniões ordinárias por ano e o número de reuniões que tinham no informe ou na pauta tema relacionados à gestão dos serviços de saúde estaduais pelas OS. 
4 Disponível em $:<$ http:// portalses.saude.sc.gov.br/ index.php?option $=$ com docman\&Itemid $=63>$.
Tabela 1 - Número de reuniões ordinárias e extraordinárias do $\mathrm{CES} / \mathrm{SC}$ com atas online por ano e número de reuniões ordinárias do CES/SC com pauta ou informe sobre as OS - 2005 a 2015

\begin{tabular}{cccc}
\hline Ano & $\begin{array}{c}\text { Reuniões } \\
\text { ordinárias do } \\
\text { CES/SC com } \\
\text { atas online }\end{array}$ & $\begin{array}{c}\text { Reuniões } \\
\text { extraordinárias do } \\
\text { CES/SC com atas } \\
\text { online }\end{array}$ & $\begin{array}{c}\text { Reuniões ordinárias } \\
\text { do CES/SC com } \\
\text { pauta ou informe } \\
\text { sobre as OS }\end{array}$ \\
\hline 2005 & 8 & 2 & 1 \\
2006 & 10 & 1 & 3 \\
2007 & 8 & - & - \\
2008 & 9 & - & 3 \\
2009 & 10 & - & 3 \\
2010 & 11 & 1 & 7 \\
2011 & 9 & 2 & 5 \\
2012 & 8 & - & 6 \\
2013 & 9 & - & 6 \\
2014 & 7 & - & 44 \\
2015 & 8 & - & \\
Total & 97 & 6 & \\
\hline
\end{tabular}

Fonte: Santa Catarina $(2015)^{4}$.

As reuniões do $\mathrm{CES} / \mathrm{SC}$ têm uma regularidade anual com discreto decréscimo em 2014 e 2015. Esse decréscimo pode se correlacionar com o crescente esvaziamento e a falta de quórum desde 2013, conforme se destaca na sequência. As reuniões extraordinárias seguem um caráter eventual. Neste levantamento das atas, sem considerar os meses mais tradicionais de férias como dezembro, janeiro e fevereiro, observaram-se vários meses sem reunião do CES. Destaca-se: em 2007, de janeiro a abril; de outubro a dezembro em 2008; abril e setembro em 2012; maio e julho em 2013; já em 2014 de agosto a dezembro.

Além da não regularidade nas reuniões do CES, que deveriam ser mensais, as atas também expressam reclamações recorrentes de conselheiros sobre a falta de quórum. Vale exemplificar com o trecho da ata 156 de 28 de outubro de 2009: 
O Conselheiro Hélio Livino sugeriu que fosse repensada a questão da falta de quórum no momento da reunião em que são feitas as leituras dos relatos das comissões; pois, segundo ele, assuntos muito relevantes são discutidos nos relatos quando deveriam ser pautados na reunião.

O Conselheiro Gilberto Scussiato classificou como falta de respeito o esvaziamento do Plenário antes do final das reuniões.

Lamentos sobre a baixa participação dos conselheiros foram evidenciados na ata 190 de 3 de abril de 2013. Por falta de quórum, ao longo da reunião, a seção foi encerrada sem aprovações e de forma antecipada em agosto, setembro e dezembro de 2013. O mesmo se repetiu em junho de 2014, conforme a ata 201.

\section{A posição do Conselho sobre o modelo de gestão por Organização Social quando a pauta tratava dos instrumentos de gestão}

O debate sobre as Organizações Sociais para fazer a gestão dos serviços de saúde iniciou no CES em janeiro de 2005, ocasião em que o Coordenador do Programa Modernização e Fortalecimento da Gestão do Estado, no governo Luiz Henrique da Silveira, apresentou a proposta de Reforma Administrativa ${ }^{5}$ do governo do Estado que estava sendo discutida na Assembleia Legislativa. Segundo o expositor, a intenção era mudar essa administração do tipo burocrático-funcional para uma gestão por objetivo, baseada em resultado.

$\mathrm{Na}$ sequência desta e das demais reuniões até 2015, essa mudança no modelo de gestão - que, particularmente na Secretaria de Saúde do Estado, significa entregar a gestão dos grandes serviços de saúde estaduais para empresas chamadas Organizações Sociais - foi parte da pauta de $40 \%$ das reuniões do CES. Os debates foram de evidentes preocupações em relação à obrigação do Estado fornecer saúde gratuita e de qualidade à população e fazer a gestão conforme prevê a
5 Do Projeto de Reforma Administrativa do governo do estado de Santa Catarina decorreu a Lei Complementar $\mathrm{n}^{\mathbf{0}} 284$, de 28 de fevereiro de 2005, que estabelece modelo de gestão para a Administração Pública Estadual e dispõe sobre a estrutura organizacional do Poder Executivo. 
6 Neste estudo das 97 reuniões analisadas, contamos $17 \mathrm{com}$ fortes debates/embates sobre os modelos de gestão: 26 de janeiro de 2005, 26 de abril de 2006, 25 de junho de 2008; no ano de 2010, nas reuniões de março, abril, maio, junho, julho, agosto, setembro e dezembro; 3 de agosto de 2011, 14 de setembro de 2011, 14 de dezembro de 2011, reunião 179, em 7 de março de 2012, reunião 180 , reunião 186, em 7 de novembro de 2012; na reunião ata 191 e 193, em 5 de junho de 2013 e em 4 de setembro de 2013 e 200, em 7 de maio de 2014. legislação do SUS, do que decorreram inúmeros embates acalorados e conflitos entre os segmentos de trabalhadores e usuários, com os gestores estaduais e os prestadores privados de serviços para o SUS ${ }^{6}$.

Nessa trajetória de embates sobre o tema das Organizações Sociais, cabe destacar que alguns representantes de trabalhadores e usuários integrantes do Conselho lideraram propostas que resultaram em medidas importantes na defesa da gestão pública estatal, aprovadas por maioria no plenário do CES. Cabendo destacar: uma Resolução em 2008 para não entregar o SAMU à gestão de OS; em 2010, a aprovação da Resolução no 03 contrária à terceirização da gestão e gerência das unidades e serviços próprios de saúde; e, em 2012, uma Resolução que determina à SES a suspensão do Edital de Concursos de Projetos SPG/SES no 001/2012 - SAMU, com imediata realização de Concurso Público.

Embora o Conselho Estadual seja um colegiado deliberativo da política estadual de saúde, que não aprovou nestes anos a entrega dos serviços de saúde de âmbito estadual a gestão por Organização Social, a Secretaria de Estado da Saúde, ignorando essas reprovações, foi progressivamente transferindo a gestão de serviços para OS. A seguir, são relacionados os serviços públicos com contrato de gestão privada, por meio de OS, vigente em 2016: a) a Fundação Hemosc e CEPON-FAHECE - assumiu, em 2007, o Centro de Pesquisas Oncológicas (CEPON) - e Centro de Hematologia e Hemoterapia de Santa Catarina (Hemosc); b) o hospital Terezinha Gaio Basso de São Miguel do Oeste passou para a Associação Beneficente Hospitalar Peritiba - rede São Camilo, contratualizado em 2010. Em maio de 2015, a gestão desse hospital foi para o Instituto Santé; c) o hospital Regional Afonso Guizzo de Araranguá a gestão foi transferida para Associação Paulista para o Desenvolvimento da Medicina - SPDM - em 2013; d) o hospital Materno Infantil Jeser Amarante de Joinville para a OS Hospital Nossa 
Senhora das Graças em 2008; e) com contrato assinado em 2010, o Hospital Regional Hans Dieter Schmidt de Joinville é administrado pela Organização Social Fundação São Paulo Apóstolo e tem por objeto a implantação e acompanhamento do processo de qualidade e humanização do hospital; f) Serviço Móvel de urgência (SAMU) - transferido para Associação Paulista para o Desenvolvimento da Medicina (SPDM) - em 2012; e g) em dezembro de 2013 o Hospital Florianópolis, teve sua gestão também transferida à Associação Paulista para o Desenvolvimento da Medicina (SPDM).

Particularmente nesse item, de forma descritiva e sequencial, apresentaremos a síntese das atas, de como o tema das Organizações Sociais perpassou o CES quando a pauta se tratava dos instrumentos de gestão: Termo de Compromisso da Gestão Estadual em relação ao Pacto de Gestão da Saúde 2006, Plano Estadual de Saúde, Proposta Orçamentária Anual, prestação de contas trimestral e Relatório de Gestão Anual.

Em 26 de março de 2008, o CES debateu o Termo de Compromisso da Gestão Estadual, no sentido de viabilizar o Pacto de Gestão da Saúde 2006. Sem colocar os detalhes dos debates, a ata registra a oposição de alguns trabalhadores e usuários acerca da gerência das unidades públicas por Organização Social. Em setembro de 2008, na apreciação da Proposta Orçamentária 2009, a ser encaminhada para Assembleia Legislativa do Estado de Santa Catarina (ALESC), o CES não aprovou integralmente e deixou itens pendentes para serem esclarecidos quanto ao financiamento das OS. Na sequência, aprovou uma proposta, feita pelo conselheiro Carreirão (trabalhador), que determina que o valor destinado às Organizações Sociais em 2009 seja o que estava previsto somente para atender o HEMOSC e CEPON, sem a inclusão do SAMU e o Hospital de Joinville.

Na plenária 155,de26 de agosto de 2009, a Coordenadora da Comissão de Acompanhamento Orçamentário, Caroline 
Junckes da Silva (trabalhadora), apresentou parecer sobre a Prestação de Contas dos $1^{\circ}$ e $2^{\circ}$ trimestres de 2009. A seguir, destacam-se alguns trechos:

Ficam mantidas as mesmas ressalvas quanto às despesas relativas à execução de convênios nas ações 5856, 5858, 5859, 5861 e 5862 (manutenção dos hospitais terceirizados) do programa 430 , em razão da solicitação de revisão constante nos pareceres dos trimestres de 2007 e 2008.

Em todas as ações citadas do programa 430 fica recomendada a revisão dos termos de convênios, apurando a relação entre serviços oferecidos, capacidade instalada e área física do patrimônio do Estado à disposição das entidades conveniadas, destacando os valores transferidos a título de custeio e manutenção.

Após a leitura, o parecer foi aprovado pelo plenário com um voto contrário e uma abstenção. No item de Prestação de Contas do $3^{\circ}$ trimestre de 2009 (reunião 160a de 24 de fevereiro de 2010), a conselheira Caroline Junckes da Silva informou que, a Comissão Permanente de Acompanhamento Orçamentário, solicitou aos técnicos da SES o detalhamento das ações 9062 da Prestação de Contas, referente a recursos para custeio da Estrutura de Saúde Administrativa das OS. $\mathrm{E}$, em função disso, a Comissão não elaborou um parecer para análise e aprovação do Pleno.

Em 29 de setembro de 2010, na reunião 167, a Gerente de Orçamento da SES, apresentou a Proposta Orçamentária para 2011 e, na sequência, as dúvidas e preocupações dos conselheiros foram inúmeras. Destaca-se, a seguir, parte das discussões dessa ata em relação aos recursos destinados às $\mathrm{OS}$, os quais, de alguma forma, refletem o debate dos CES desde 2008:

A Diretora Geral disse que as OS são entidades qualificadas com base na legislação. Explicou que a SES publica os editais para o concurso de projetos para que as OS se habilitem e apresentem propostas para 
gestão; que todas as ações são baseadas em contrato de gestão. Esclareceu que não há repasse de recursos sem que antes haja uma prestação de contas por parte das entidades. Informou que as Organizações Sociais estão todas relacionadas no site da SES, bem como os contratos de gestão.

$\mathrm{Na}$ sequência, o Conselheiro Carreirão lembrou que na sessão de julho o Conselho aprovou uma Resolução contrária ao modelo de gestão através de OS e, mesmo assim, a Secretaria insiste em não cumprir a decisão do CES. Enfatizou que o Estado não pode terceirizar a atividade-fim e, por esta razão, a gestão através das OS é ilegal. Carreirão manifestou seu voto contrário à peça orçamentária por conter repasses às OS.

A Conselheira Caroline Junckes disse que a Comissão de Acompanhamento Orçamentário vem reiteradamente expondo em seus pareceres à necessidade de fazer a revisão e o detalhamento dos convênios, porém isso não é feito. Questionou o porquê de a Secretaria não considerar a vontade do Controle Social, que se manifestou através de Resolução contrário à contratualização com organizações sociais. A Diretora Geral da SES, Rosina Moritz, ressaltou que refutar, negar, dizer que não dá é muito fácil. Há que se apresentar alternativas e propostas consistentes. Disse que tornar a Rede Hospitalar 100\% pública é pegar orçamento e aplicar única e exclusivamente nos hospitais estadualizados. Enfatizou que a SES tem uma grande preocupação com situações de inoperância e ineficácia na Rede Pública, e que essa preocupação não é só de Santa Catarina [...]. Findadas as discussões, o Conselho aprovou duas Resoluções. Uma solicitando a revisão e o detalhamento dos contratos e convênios, e outra cobrando maior eficiência da Mesa de Negociação Permanente do SUS em relação à negociação salarial dos servidores.

Em 14 de dezembro de 2011, na reunião 179, o CES debateu sobre a Prestação de contas do primeiro e segundo trimestres de 2011, conforme parecer apresentado pela Comissão de Acompanhamento Orçamentário. 
Da análise da documentação do $1^{\circ}$ Trimestre: Com relação à Prestação de Contas do $1^{\circ}$ Trimestre de 2011, a Comissão sugere a sua aprovação, com RESTRIÇÃO a Ação 9062 - Subvenção Financeira às Organizações Sociais - do Programa 430 por contrariar a Resolução 003/2010 e sentença judicial transitada em julgado que proíbe a contratação de OS. Da análise da documentação do $2^{\circ}$ Trimestre: Com relação a Prestação de Contas do 2o Trimestre de 2011, a Comissão sugere a sua aprovação, com RESTRIÇÃO à Ação 9062 - Subvenção Financeira às Organizações Sociais - do Programa 430, por contrariar a Resolução 003/2010 e sentença judicial transitada em julgado que proíbe a contratação de OS.

$\mathrm{Na}$ sequência da apresentação do parecer, vários conselheiros (Luiz Antônio da Silva - usuário, Simone Bihain Hagemann - trabalhadora, Jaqueline Nehring - gestão/ Ministério da Saúde) se manifestaram pela não aprovação. O conselheiro Jorge Cobra (trabalhador), que apresentou o Parecer, solicitou a retirada de pauta; Gabriel Luckmann sugeriu que as Prestações de Contas sejam submetidas à votação e por fim a Conselheira Rosina Moritz solicitou vistas ao Parecer.

Em 7 de março de 2012 retorna a pauta do CES, reunião 180, a Prestação de contas do primeiro e segundo trimestres de 2011, o represente da Comissão de Acompanhamento Orçamentário lê o mesmo parecer apresentado na reunião de 14 de dezembro de 2011. No debate o Conselheiro João Pedro Carreirão Neto disse que, se há contrariedade a uma Resolução do CES e a uma Sentença Judicial transitada em julgado, proferida pelo TRT, não há possibilidade de aprovação. Sugeriu a reprovação das Prestações de Contas. Segundo a Conselheira Simone Hagemann, outras Prestações de Contas foram aprovadas com ressalvas ou restrições; porém, nada foi feito no sentido de corrigir o que foi apontado pelo Conselho, que também sugeriu a reprovação. O Conselheiro Walter Gomes (gestor SES) ressaltou que, no entendimento 
da Procuradoria Geral do Estado (PGE) à referida sentença, há um recurso que ainda não foi julgado. Após as manifestações dos Conselheiros, a Vice-Presidente do CES/SC, Caroline Junckes da Silva, submeteu ao Pleno a aprovação das Prestações de Contas do $1^{\circ}$ e $2^{\circ}$ Trimestres de 2011 . Em relação ao $1^{\circ}$ Trimestre, as contas foram rejeitadas por maioria dos Conselheiros presentes (13 votos), com seis votos pela aprovação, de acordo com o Parecer, e duas abstenções. Quanto ao 2o Trimestre, as contas foram rejeitadas, também por maioria (14 votos), com seis votos pela aprovação, de acordo com o Parecer, e uma abstenção. O Conselheiro Acélio Casagrande (gestor SES) alertou para os problemas que uma rejeição de contas pode acarretar em relação à captação de recursos. Enfatizou que a restrição de um item não pode comprometer o conjunto de todas as contas.

Em 6 de junho de 2012, no item de apreciação e aprovação do Relatório Anual de Gestão 2011, foram feitos longos debates sobre a falta de esclarecimento dos conselheiros sobre a matéria e, também, sobre o descumprimento da Resolução 03/2010/CES/SC; mas, a reunião deu-se por encerrada quando se constatou que não havia mais quórum para deliberações. O Relatório Anual de Gestão 2011 voltou à pauta do CES em 1 de agosto de 2012, na reunião 184. O parecer elaborado de forma conjunta pelas Comissões do CES posiciona-se em favor da reprovação do Relatório. Entre os inúmeros argumentos levantados, destaca-se que:

O Conselheiro João Pedro Carreirão Neto reconheceu que a elaboração do Relatório de Gestão tem melhorado muito e elogiou a forma transparente com que foi apresentado; porém, disse que o que está se aprovando não é a maneira com que o relatório foi elaborado, mas sim o que nele está contido. Enfatizou que somente o fato de as contas do $3^{\circ}$ e $4^{\circ}$ trimestres de 2011 não terem sido apresentadas seria motivo para a reprovação do RAG. 
Por fim, a presidência submeteu à votação o parecer conjunto das Comissões, que opina pela reprovação do Relatório Anual de Gestão 2011. Por 13 votos a oito, com duas abstenções, o parecer foi aprovado. Ou seja, o Relatório Anual de Gestão 2011, não foi aprovado.

$\mathrm{Na}$ Reunião 189, em 6 de março de 2013, o Conselheiro Braz Vieira (prestador), membro da Comissão de Acompanhamento Orçamentário apresentou várias solicitações de informações quanto ao andamento das obras, a relação de recursos e a produção hospitalar em SC, para complementar o Relatório Anual de Gestão 2011. Findadas as várias interpelações de conselheiros, o Conselho aprovou os encaminhamentos da Comissão de Acompanhamento Orçamentário.

$\mathrm{Na}$ ata 190 do CES, em 3 de abril de 2013, no item de apresentação Programação Anual de Saúde 2013, apresentase parte do debate:

Para o Conselheiro Luiz Antônio da Silva, o Plano Estadual de Saúde (2012-2015) aprovado pelo CES diz que todas as unidades que estão sob gestão de organizações sociais devem voltar a ser geridas pelo Estado. Lembrou da Carta Recomendatória do Ministério Público do Trabalho (33.326/2011 do MPTSC), a qual alerta para a responsabilidade dos conselheiros em votar as matérias. Falou em relação ao Contrato de Gestão do SAMU e os recursos destinados. Questionou a manutenção das unidades sob gestão da SES, quais são elas e quais as organizações sociais que administram as unidades. Ainda perguntou do total de recursos para unidades assistenciais, quanto é destinado às unidades administradas pela SES e quanto para as administradas por OS. Respondendo os questionamentos do Conselheiro, a Gerente de Coordenação das Organizações Sociais, Cristina Machado Pires, informou que são destinados para unidades gerenciadas por organizações sociais 24 milhões e 860 mil reais por mês. Com relação ao SAMU, o Gerente Cesar Augusto Korczaguin explicou que a gestão do sistema SAMU é do Estado, a Organização Social operacionaliza o sistema. 
Após os questionamentos, as sugestões e explicações por parte dos conselheiros e equipe técnica da SES, a presidência da sessão submeteu a Programação Anual de Saúde 2013 à aprovação do Pleno. Com 15 votos favoráveis, dois contrários e cinco abstenções, a Programação Anual de Saúde 2013 foi aprovada. Em sua declaração de voto, o Conselheiro Luiz Antônio da Silva (usuário) chamou a atenção referente à Carta Recomendatória do Ministério Público. Segundo ele, o Estado foi condenado em uma Ação Civil Pública por terceirizar os serviços de saúde e, em função disso, seu voto é contrário ao repasse de recursos às organizações sociais que constam da Programação Anual. A Conselheira Vera Castellain (usuária) declarou seu voto parabenizando a todos que contribuíram para que a Programação Anual tenha sido a melhor possível; porém, para ela ficou um ponto de interrogação na gestão e operacionalização do SAMU.

No item II da pauta na ata 191 do CES, em 5 de junho de 2013:

[...] a Coordenadora da Comissão de Acompanhamento Orçamentário, Jaqueline Nehring, explicou que o Relatório acerca da Prestação de Contas da SES - Primeiro e Segundo Quadrimestres/2012 - não teve aprovação unânime entre os membros da Comissão e leu o Parecer, conforme segue, com a presença dos técnicos das áreas da SES para eventuais esclarecimentos. [...] Voto e encaminhamento: a CPAOF, em análise aos documentos recebidos, opina e encaminha ao Pleno do CES a indicação de REPROVAÇÃO da Prestação de Contas do $1^{\circ}$ e 20 Quadrimestres de 2012, justificada na destinação de recursos do FES ao Programa 400, Ação 11441 Subvenção financeira às Organizações Sociais por ser contrário ao consolidado no Plano Estadual de Saúde aprovado para o período 2012/2015 e na Resolução CES no 003/2010.

Após apresentação da Comissão de Acompanhamento Orçamentário, o debate na plenária do Conselho foi longo envolvendo conselheiros de vários segmentos, destacando 
apenas a fala de um representante da gestão: "O Conselheiro Cyro Soncini disse que esse assunto é anualmente debatido e ressaltou que não há ilegalidade. Falou que, como representante do Sindicato dos Médicos, prefere a gestão pública; porém, quem tem que dizer se o repasse as OS é inconstitucional ou não é o STF [...]".

$\mathrm{Na}$ sequência, a Presidência da sessão submeteu ao Conselho as Prestações de Contas da SES - $1^{\circ}$ e $2^{\circ}$ Quadrimestres/2012, as quais foram aprovadas com ressalva por dez votos a sete, com uma abstenção.

Polêmica semelhante aconteceu na reunião 193, de 4 de setembro de 2013, quando o Coordenador da Comissão de Acompanhamento Orçamentário, informou que a Comissão, após analisar as Prestações de Contas do $3^{\circ}$ quadrimestre de 2012 e $1^{\circ}$ de 2013, recomenda ao Pleno a aprovação das referidas Prestações de Contas com ressalvas devido aos repasses às Organizações Sociais. No processo de votação, as Prestações de Contas da SES - 30 e 4o Quadrimestre/2012 e $1^{\circ}$ Quadrimestre/2013 foram aprovadas com ressalva por 12 votos a oito, com uma abstenção.

Em um período em que o Conselho Estadual de Saúde não instalou suas reuniões ou várias delas foram encerradas ao meio por falta de quórum, aliada aos processos de renovação de gestões, o cenário político do Conselho Estadual de Saúde se alterou. Os embates políticos em relação à direção da gestão pública do SUS em Santa Catarina diminuíram. Nesse contexto, a Comissão Permanente de Orçamento passa a ser assumida por pessoas mais alinhadas à gestão da Secretaria de Estado da Saúde. As atas dos anos de 2014 e 2015 revelam menos polêmica no debate sobre a Programação Anual de Saúde e Prestação de contas quadrimestrais da SES. A título de exemplo a Programação Anual de Saúde/2014, foi aprovada por maioria (Ata 197, em 5 de fevereiro de 2014). Em 3 de setembro de 2014, na ata 203, o parecer da Comissão de Acompanhamento Orçamentário em relação ao Relatório 
Anual de Gestão - 2013 recomenda a REPROVAÇÃO; mas, após as manifestações dos conselheiros, a Presidente da sessão submeteu à aprovação do Pleno e com 16 votos, o Relatório Anual de Gestão - SES/2013 foi aprovado com ressalvas.

\section{Considerações finais}

Este texto procurou refletir sobre como o tema dos serviços públicos estaduais de saúde entregues à gestão de Organizações Sociais foi estudado, debatido e deliberado pelo Conselho Estadual e Saúde de Santa Catarina entre 2005 e 2015, quando este tipo de serviço estava nos debates sobre os instrumentos de gestão. Em grande medida, o que as atas estudadas refletem é que o tema perpassou a pauta com muitas tensões e debates acalorados em termos de perspectiva política sobre a gestão dos serviços do SUS no estado. A descontinuidade, ao longo destes 11 anos, também foi outra marca do debate das OS no CES/SC. No conjunto, observaram-se as atas mais breves, que são menos descritivas desde 2013. A partir deste ano, também se evidencia um decréscimo no debate e das polêmicas sobre o tema das OS no Conselho, assim como também não se tomou nenhuma decisão contrária a essa forma de gestão.

A pesquisa observou descontinuidade do debate e infere que se deve às trocas de gestões da SES (secretário estadual e gerências) e, também, às novas gestões do Conselho Estadual que se renovam a cada dois anos. Mas, esta descontinuidade revela uma dupla face quando se analisa a partir da posição dos segmentos que compõem este colegiado: a) os gestores e prestadores privados para o SUS na sua descontinuidade parecem que quando retomam o debate seguem a mesma perspectiva e com acúmulo; b) já no segmento dos usuários e trabalhadores, pela renovação de pessoas e entidades, a descontinuidade parece revelar desconhecimento do tema e certa regressividade no debate em termos de perspectiva política. 
No entanto, nenhuma destas duas faces pode ser analisada sem considerar a participação destes segmentos que compõem o Conselho nas decisões sobre as políticas sociais no Brasil na relação com traços históricos da nossa cultura política que sempre excluiu deste espaço decisões usuários e trabalhadores da área. $\mathrm{Na}$ trajetória conselhista, após Constituição de 1988, ainda que tenha colocado mudanças significativas ao contemplar estes sujeitos sociais no campo da deliberação das políticas sociais, evidenciam-se muitos elementos de continuidade de gestão pública centralizadora e autoritária.

No entanto, nos grandes embates que usuários e trabalhadores travaram para defender uma gestão estatal e com base na Lei no 8.080/90, muitas vezes seus comentários pareciam desinformados, outras vezes deram um tom imediatista, ingênuo ou espontaneísta. Quando o item da pauta da reunião do CES era algum instrumento de gestão para aprovar, foram contínuas e persistentes intervenções de usuários e trabalhadores questionando a legalidade e a legitimidade das OS realizando os serviços do SUS em Santa Catarina. Estes questionamentos provocavam incômodo na forma de a presidência do Conselho conduzir a pauta e coordenar a reunião. Igualmente, pareciam incomodados a secretaria executiva do CES, os outros representantes do gestor e os prestadores privados para o SUS. No entanto, como já ressaltamos, as resoluções aprovadas pelo CES para defender a gestão pública estadual do SUS em Santa Catarina resultaram de propostas de usuários e trabalhadores.

A pesquisa revelou que os gestores, por sua vez, expressaram-se nas reuniões do CES de forma bastante contida, falando pouco e bastante cercados de termos técnicos e do arcabouço legal restrito à Lei de Responsabilidade Fiscal, à Lei de Licitações e ao Estatuto do Servidor Público Estadual. Os prestadores privados para o SUS também na plenária se expressaram pouco, normalmente apelavam para 
que se evitassem polêmicas e uso de expressões que chamam de ideológicas. Para prestadores e gestores, a lei está acima da ideologia e do debate político, pois o modelo de gestão por OS está previsto em lei. Ressaltavam que tratar de gestão por OS não é privatização e que é uma opção técnica do governo realizar essa forma de gestão dos serviços. Outras falas dos prestadores seguiam no sentido de reforçar os argumentos normativos citados pelo gestor. A participação deste segmento ganha uma particularidade e é muito semelhante nos vários temas da pauta do CES/SC, já que se ressaltam enfaticamente os serviços que prestam ao SUS em Santa Catarina e que os recursos que recebem para esta finalidade são insuficientes. Em síntese, os gestores e prestadores nas plenárias do Conselho ao tratar dos temas desta forma despolitizam e dão a impressão de que gestão pública é meramente técnica e operacional, o que expressa o vínculo com projeto gerencialista antes apresentado. A responsabilidade pública dos gestores com a implementação do SUS e garantia de direitos sociais por meio dos instrumentos de gestão e serviços, fica submetida à agilidade operacional, que entendem que pode ser conseguida com a mudança do modelo de gestão. A Lei no 8.080/90 em seus fundamentos e princípios não foi referenciada em nenhum momento por estes dois segmentos. Esta é uma expressão de que as mudanças de modelo de gestão pública, para atender às necessidades dos novos tempos, desvinculam-se de princípios e de direitos básicos de cidadania e das necessidades de saúde.

Considerando o papel do CES e as significativas deliberações aprovadas contra a gestão de serviços por OS, nas atas e nas ações do executivo estadual observaram-se várias contratualizações com Organizações Sociais, que a gestão da SES seguiu à revelia do que se deliberou nesse Colegiado. Isso mais uma vez comprova a reprodução de elementos tradicionais (autoritarismo, centralização etc.) de nossa cultura política na gestão das políticas sociais. E os espaços participativos com usuários e trabalhadores viram objeto de 
retórica despolitizada ou figurantes de plenárias mensais que cumprem uma determinação legal (Lei no 8.142/90).

Nesse sentido, voltando operacionalmente para a gestão democrática na saúde, as equipes técnicas planejamento que sistematizam e coordenam os instrumentos de gestão tem que dar a direção para implantar concretamente os direitos de cidadania e princípios do SUS. Nesse caso, entendemos que a democracia deve ser condição social e não apenas método nesta direção (NETTO, 1990). Nesse sentido, a participação em uma lógica de cidadania e democracia significa a possibilidade de os indivíduos apropriarem-se dos bens socialmente criados e de atualizarem todas as potencialidades de realização humana abertas pela vida social em cada contexto histórico determinado. No caso da saúde, é trabalhar na direção da universalização do acesso em cada nível e complexidade dos serviços, de acordo com as condições técnicas, de profissionais, de equipamentos e medicamentos que a sociedade conseguiu produzir (riqueza socialmente produzida). Sabemos que a lógica do mercado pressiona para impor e vender suas inovações gerenciais e de produtos, mas uma gestão tem de ter condições técnicas de avaliar de acordo com o perfil epidemiológico, os princípios organizacionais e doutrinários do SUS o que absorver para garantir atendimento universal e integral. $\mathrm{Na}$ lógica mercadológica da indústria de equipamentos médicohospitalares, a integralidade parece não ter limites no âmbito da alta complexidade. No caso, os defensores do projeto gerencialista impõem a redução de custos para as instituições (uma das estratégias tem sido entregar a gestão pública para as empresas chamadas OS); contudo, não as relacionam com as nossas históricas desigualdades de acesso aos serviços de saúde, nem com a determinação social da saúde. Só que garantir a implementação do SUS como direito de todos, em uma perspectiva de saúde coletiva e de primazia da atenção básica, sem negligenciar a alta complexidade, implica uma gestão com equipe técnica atuando fortemente nessa direção. $\mathrm{E}$ os instrumentos de gestão são documentos técnicos e políticos que podem garantir a implementação dos serviços 
de acordo com os fundamentos do SUS. No entanto, como vimos no estudo das atas do CSES/SC, a ênfase gerencialista da modernização operacional e técnica se sobrepõe às necessidades públicas e coletivas de saúde.

Logo, é imprescindível que os Conselhos mantenham a sua função primordial de permitir, sem ter a necessidade de refazer todo o processo histórico já percorrido, e que a sociedade brasileira se aproprie deste patrimônio que é o SUS, isto é, aproprie-se daqueles elementos que o Movimento da Reforma Sanitária já produziu e elegeu como legítimos para garantir as necessidades de saúde, bem como desenvolvam a capacidade para contemplar as necessidades coletivas e públicas de saúde e não as necessidades de reprodução ampliada do capital. $\mathrm{O}$ acesso aos serviços de saúde como bem cultural dos homens e mulheres, resultado da sua produção histórica, é uma das condições que possibilita o acesso à distribuição dos bens materiais coletivamente produzidos pela humanidade. Além disso, a experiência histórica tem mostrado que serviços de saúde regidos pelo direito privado não cumprem esta função.

Nesta direção, uma gestão democrática que cumpre uma finalidade pública voltada aos interesses e às necessidades das classes populares, na sua dinâmica de gestão, potencializa a vocalização das necessidades sociais expressas em seus diferentes espaços de organização, reconhece e explicita suas demandas nos instrumentos de gestão como Planos Plurianuais de Governo, na Programação Anual de Atividades e na Programação Orçamentária. A participação popular e a existência dos conselhos deliberativos propicia um processo de redefinição da relação entre o Estado e a sociedade civil na dinâmica de gestão das políticas sociais.

\section{Referências}

BÓRON, Atilio. A trama do Neoliberalismo: mercado, crise e exclusão social. In: GENTILI, Pablo; SADER, Emir (Org.). Pósneoliberalismo: as políticas sociais e o estado democrático. 3. ed. Rio de Janeiro: Paz e Terra, 1996. p. 139-180. 
BRASIL. Lei no 8.080, de 19 de setembro de 1990. Dispõe sobre as condições para a promoção, proteção e recuperação da saúde, a organização e o funcionamento dos serviços correspondentes e dá outras providências. Diário Oficial da República Federativa do Brasil, Brasília, DF, 20 set. 1990. Disponível em: <http://www. planalto.gov.br/ccivil_03/leis/L8080.htm>. Acesso em: 14 maio 2015.

Lei no 9.6378, de 15 de maio de 1998. Dispõe sobre a qualificação de entidades como organizações sociais, a criação do Programa Nacional de Publicização, a extinção dos órgãos e entidades que menciona e a absorção de suas atividades por organizações sociais, e dá outras providências. Diário Oficial da República Federativa do Brasil, Brasília, DF, 25 maio 1998. Disponível em: <http://www.planalto.gov.br/ccivil_03/leis/L9637. htm>. Acesso em: 13 maio 2015.

. Decreto no 3.100, de 30 de junho de 1999. Regulamenta a Lei no 9.790, de 23 de março de 1999, que dispõe sobre a qualificação de pessoas jurídicas de direito privado, sem fins lucrativos, como Organizações da Sociedade Civil de Interesse Público, institui e disciplina o Termo de Parceria, e dá outras providências. Diário Oficial da República Federativa do Brasil, Brasília, DF, 13 jul. 1999. Disponível em: <http://www.planalto.gov.br/ccivil_03/ decreto/d3100.htm>. Acesso em: 13 maio 2015.

CORREIA, Maria Valéria; SANTOS, Viviane Medeiros do. Privatização da saúde via novos modelos de gestão: as Organizações Sociais em questão. In: BRAVO, Maria Inês Souza Bravo; ANDREAZZI, Maria de Fátima Siliansky; MENEZES, Juliana Souza Bravo de; LIMA, Joseane Barbosa de; SOUZA, Rodriane de Oliveira (Org.). A mercantilização da saúde em debate: as Organizações Sociais no Rio de Janeiro. 1. ed. Rio de Janeiro: UERJ, Rede Sirius, 2015.p. 33-41.

FAHECE. Estatuto. Florianópolis, 8 jun. 2006. Disponível em: <http://fahece.web753.kinghost.net/wp-content/uploads/estatuto_ fah.pdf>. Acesso em: 27 maio 2015.

FERNANDES, Florestan. A revolução burguesa no Brasil. Ensaio de interpretação sociológica. Prefácio José de Souza Martins. 5. ed. 2. reimpr. São Paulo: Globo, 2006.

FRENTE NACIONAL CONTRA A PRIVATIZAÇÃO DA SAÚDE. Contra Fatos Não Há Argumentos. 2015. Disponível em: <http://www.contraprivatizacao.com.br>. Acesso em: 13 maio 2015. 
GRANEMANN, Sara. Fundações Estatais: Projeto de Estado do Capital. In: BRAVO, Maria Inês Souza; MENEZES, Juliana Souza (Org.). Cadernos de Saúde: Saúde na atualidade: por um sistema único de saúde estatal, universal, gratuito e de qualidade. 1. ed. Rio de Janeiro: UERJ/Rede Sirius, set. 2011. p. 50-55. Disponível em: <http://fopspr.wordpress.com/2008/08/16/texto-sobre-fundacoesestatais-de-direito-privado-fedp/>. Acesso em: 13 maio 2015.

HEMOSC. Disponível em: <http://www.hemosc.org.br>. Acesso em: 13 maio 2015.

IANNI, Octavio. O ciclo da revolução burguesa. Rio de Janeiro: Editora vozes, 1984.

KRÜGER, Tânia Regina. As Conferências de saúde e os planos municipais de saúde: considerações sobre o significado da participação popular em Santa Catarina. 1. ed. Florianópolis: DIOESC, 2012.

MOTA, Ana Elizabete; AMARAL, Ângela Santana do (Org.). Serviço Social brasileiro nos anos 2000: pelejas e desafios. Recife: UFPE, 2014. p. 45-62.

NETTO, José Paulo. Notas sobre democracia e transição socialista. A redefinição da democracia. In: Democracia e transição socialista. Belo Horizonte: Oficina de Livros, 1990. p. 69-127.

NOGUEIRA, Marco Aurélio. As possibilidades da política. São Paulo: Paz e Terra, 1998.

PRADO JR., Caio. Formação do Brasil Contemporâneo. Entrevista Fernando Novais; posfácio Bernardo Ricupero. São Paulo: Companhia das Letras, 2011.

SALES, Teresa. Raízes da desigualdade social na cultura política brasileira. 1993. Disponível em: <http://www.anpocs.org.br/portal/ publicacoes/rbcs_00_25/rbcs25_02.htm>. Acesso em: 6 maio 2016.

SANTA CATARINA. Lei no 12.929, de 4 de fevereiro de 2004. Institui o Programa Estadual de Incentivo às Organizações Sociais. Diário Oficial do Estado, Florianópolis, 4 fev. 2004. Disponível em: <http://200.192.66.20/alesc/docs/2004/12929_2004_lei.doc>. Acesso em: 6 maio 2016.

Lei no 13.343, de 10 de março de 2005. Altera a Lei no 12.929, de 2004, que institui o Programa Estadual de Incentivo às Organizações Sociais. Diário Oficial do Estado, Florianópolis, 10 
mar. 2005. Disponível em: <https://www.crefsc.org.br/principal/ wp-content/uploads/2016/04/lei_n_13.343.pdf >. Acesso em: 6 maio 2016.

Lei $\mathrm{n}^{\circ} 13.720$, de 2 de março de 2006. Altera a Lei ${ }^{\circ}$ 12.929, de 2004, que institui o Programa Estadual de Incentivo às Organizações Sociais. Diário Oficial do Estado, Florianópolis, 2 mar. 2006. Disponível em: <http://200.192.66.20/alesc/ docs/2006/13720_2006_Lei.doc>. Acesso em: 6 maio 2016.

Contrato de Gestão CEPON 002/2007. Disponível em: $\quad$ http://portalses.saude.sc.gov.br/index.php?option=com docman\&task $=$ cat_view\&gid $=1057 \& I$ temid $=547>$. Acesso em: 2 jul. 2015.

. Secretaria do Estado da Saúde.Atas CES. 2015. Disponível em: <http://portalses.saude.sc.gov.br/index.php?option=com docman\&Itemid=63>. Acesso em: 15 maio 2016.

Contrato de Gestão CEPON 002/2016. Disponível em: $\quad<$ http://portalses.saude.sc.gov.br/index.php?option=com docman\&task $=$ cat_view\&gid $=1057 \& I t e m i d=547>$. Acesso em: 2 jul. 2017.

. Secretaria do Estado de Planejamento. Ações. Organizações sociais. Sobre Organizações Sociais. 2017. Disponível em: <http:// www.spg.sc.gov.br/index.php/acoes/19-organizacoes-sociais>. Acesso em: 2 jul. 2015.

SOUTO MAIOR, Jorge Luiz. Desinformação e soberba do Estadão. Carta Maior. 1 fev. 2017. Disponível em: <http://www. cartamaior.com.br/?/Editoria/Politica/Desinformacao-e-soberbado-Estadao/4/37651>. Acesso em: 18 maio 2017.

SOUZA FILHO, Rodrigo de. Estado, burocracia e patrimonialismo no desenvolvimento da administração pública brasileira. 2006. 398 f. Tese (Doutorado em Serviço Social) Programa de Pós-graduação em Serviço Social, Universidade Federal do Rio de Janeiro, Rio de Janeiro, 2006.

Gestão Pública \& democracia: a burocracia em questão. 2 . ed. Rio de Janeiro: Lumen Juris, 2013.

SPDM. SAMU Santa Catarina. Disponível em: <http://www. spdmpais.org.br/site/samu-santa-catarina.html>. Acesso em: 3 jul. 2015.

Submetido em: 06/03/2017

Aceito em: 12/07/2017 


\title{
SOCIAL ORGANIZATIONS AND MANAGEMENTTOOLS: THE DEBATE IN THE STATE HEALTH COUNCIL - CES/SC
}

\begin{abstract}
The purpose of this article is to know and reflect how the State Health Council of Santa Catarina (CES/SC), considering the management tools (State Health Plan, Annual Health Program, Four-Month Period Accountability and Annual Management Report), debated, questioned and deliberated on the state health services delivered to the management of Social Organizations (SO) - in a context of serious affront to the foundations of the Unified Health System (SUS). For this study, the minutes available online from the CES/SC, from 2005 to 2015, were consulted. In the text, we initially present the regulatory mark and reflections on the meaning of Social Organizations in SUS services as a form of non-classical privatization of public services. From the study of the minutes resulted an item on the subject of how the management of the state health services under the management of $\mathrm{SO}$ was discussed and decided by the State Health Council when the agenda was the management tools. The tensions in terms of political perspective, the discontinuities of the topic at hand, the managerialist and legalistic emphasis are the main marks of the SO debate in the $\mathrm{CES} / \mathrm{SC}$.
\end{abstract}

Keywords: SUS. Social Organizations. Management Tools. Health Council. 